\title{
Fossil vesicomyid bivalves from Miocene hydrocarbon seep sites, North Island, New Zealand
}

Kazutaka Amano, Kristian P. Saether, Crispin T.S. Little, and Kathleen A. Campbell Acta Palaeontologica Polonica 59 (2), 2014: 421-428 doi: http://dx.doi.org/10.4202/app.2012.0070

Two fossil species of vesicomyids are described from Lower to Middle Miocene hydrocarbon seep carbonates in eastern North Island, New Zealand. One elongate species is proposed as a new genus and species: Notocalyptogena neozelandica. The other species probably belongs to the genus Pliocardia, but due to poor preservation is not identified further. The composition of this Miocene vesicomyid seep fauna differs from that found in modern New Zealand seeps located on the offshore Hikurangi convergent margin, which contain the genera Calyptogena, Archivesica, and Isorropodon. The fossil fauna went extinct locally after the Middle Miocene and has been since replaced by the modern vesicomyid taxa.

Key words: Mollusca, Bivalvia, Vesicomyidae, hydrocarbon seep, Miocene, New Zealand.

Kazutaka Amano [amano@juen.ac.jp], Department of Geoscience, Joetsu University of Education, 1 Yamayashiki, Joetsu 943-8512, Japan; Kristian P. Saether [kris.saether@gmail.com] and Kathleen A. Campbell [ka.campbell@auckland.ac.nz ], School of Environment, Faculty of Science, University of Auckland, Private Bag 92019, Auckland Mail Centre, Auckland 1142, New Zealand; Crispin T.S. Little [earctsl@leeds.ac.uk], School of Earth and Environment, University of Leeds, Leeds LS2 9JT, United Kingdom.

This is an open-access article distributed under the terms of the Creative Commons Attribution License (for details please see creativecommons.org), which permits unrestricted use, distribution, and reproduction in any medium, provided the original author and source are credited. 
